\title{
SUPERAÇÃO DA DORMÊNCIA E QUALIDADE DE LUZ NA GERMINAÇÃO DE SEMENTES DE Murdannia nudiflora (L.) Brenans ${ }^{1}$
}

\author{
DANILO APARECIDO FERRARESI², OSCAR MITSUO YAMASHITA ${ }^{3}$, \\ MARCO ANTONIO CAMILLO DE CARVALHO ${ }^{3}$
}

\begin{abstract}
RESUMO - O estudo da fisiologia germinativa de sementes, principalmente de plantas daninhas, tem se intensificado, devido à importância do conhecimento sobre este assunto para melhorar e criar novas técnicas de manejo de plantas daninhas. Os experimentos foram conduzidos em duas etapas objetivando-se estudar os efeitos de diferentes métodos de quebra de dormência das sementes e da qualidade da luz de Murdannia nudiflora (L.) Brenans. Na primeira etapa, os tratamentos constituíram de sete métodos de quebra de dormência: escarificação mecânica, com lixa por 60 segundos; escarificação química, com imersão em ácido sulfúrico por 30, 60 e 300 segundos, hidróxido de sódio a $20 \%$ por 5,15 e 25 minutos, hipoclorito de sódio a 2,5\% por 24 horas, nitrato de potássio $(20 \mathrm{mM})$ por 24 e 48 horas, ácido giberélico $(1 \mathrm{mM})$ por 24 horas e testemunha. O delineamento estatístico utilizado foi o inteiramente ao acaso, com quatro repetições. Foram contadas diariamente as sementes germinadas, e no final de 30 dias, determinou-se o IVG. Na segunda etapa, os tratamentos de qualidade da luz constaram de 5 filtros de luz (azul, verde, vermelho, transparente e ausência total de luz). Maior porcentagem de germinação das sementes foi obtida utilizando escarificação mecânica (lixa) (84\%), seguido da escarificação química com ácido sulfúrico por 1 minuto (74\%), hipoclorito de sódio por 24 horas (46\%) e hidróxido de sódio por 25 minutos (26\%). Quanto a porcentagem de germinação de sementes em função da qualidade de luz verificou-se as seguintes porcentagens de germinação: azul - com refletividade máxima a $450 \mathrm{~nm}$ (58\%), verde - $500 \mathrm{~nm}$ (64\%), vermelho - 700 $\mathrm{nm}(75 \%)$, ausência de luz (0\%) e transparente - sem absortividade na região de $380 \mathrm{~nm}$ a $760 \mathrm{~nm}$ (87\%). Sementes de M. nudiflora podem ser consideradas fotoblásticas positivas.
\end{abstract}

Termos para indexação: fotoblastismos, escarificação mecânica, fitocromo.

\section{OVERCOME DORMANCY AND QUALITY OF LIGHT IN THE GERMINATION OF Murdannia nudiflora (L.) Brenans SEEDS}

\begin{abstract}
The study of seed germination physiology, especially of weeds, has been intensified due to the importance of knowledge on this subject to improve and create new techniques for weed management. Experiments were conducted in two phases to study the effects of different methods of overcoming the dormancy of Murdannia nudiflora (L.) Brenans seeds and light quality. In the first stage, the treatments consisted of seven methods of overcoming dormancy: mechanical scarification with sandpaper for 60 seconds; chemical scarification with sulfuric acid for 30, 60 and 300 seconds, sodium hydroxide $20 \%$ for 5,15 and 25 minutes, sodium hypochlorite $2.5 \%$ for 24 hours, potassium nitrate $(20 \mathrm{mM})$ for 24 and 48 hours, gibberellic acid ( $1 \mathrm{mM})$ for 24 hours and witness. A randomized complete statistical design was used with four repetitions. The germinated seeds were counted daily, and at the end of 30 days, the IVG was determined. In the second step, the quality of the light
\end{abstract}

\footnotetext{
${ }^{1}$ Submetido em 16/12/2008. Aceito para publicação em 30/08/2009. Monografia apresentada pelo primeiro autor para obtenção de título de Eng. Agrônomo pela Universidade do Estado de Mato Grosso.
}

${ }^{2}$ Eng. Agr. Plante Bem Assessoria e Consultoria Rural, 78580-000 - Alta Floresta-MT. daniloferraresi@hotmail.com.
${ }^{3}$ Eng. Agr. Dr. Prof. Departamento de Agronomia - Universidade do Estado de Mato Grosso - Campus Universitário de Alta Floresta, Caixa postal 324, 78580-000 - Alta Floresta-MT. yama@unemat.br; marcocarvalho@unemat.br. 
treatments consisted of 5 light filters (blue, green, red, transparent, and total absence of light). A higher percentage of seed germination was obtained using mechanical scarification (sanding) (84\%), followed by chemical scarification with sulfuric acid for 1 minute (74\%), sodium hypochlorite for 24 hours (46\%) and sodium hydroxide for 25 minutes $(26 \%)$. Quanto a porcentagem de germinação de sementes em função da qualidade de luz verificou-se as se Regarding the percentage of seed germination in function of the light quality of light,d the following germination percentages were observed: blue - with maximum reflectivity at $450 \mathrm{~nm}(58 \%)$, green - $500 \mathrm{~nm}(64 \%)$, red - $700 \mathrm{~nm}$ (75\%), absence of light ( $0 \%$ ) and transparently - without absorptivity in the region of $380 \mathrm{~nm}$ to 760 $\mathrm{nm}(87 \%)$. Seeds of M. nudiflora can be considered positive photoblastics.

Index terms: photoblastism, mechanical scarification, phytochrome

\section{INTRODUÇÃO}

Nos últimos cinco anos na região norte mato-grossense, tem sido verificado a crescente infestação de uma espécie de planta daninha pertencente à família Commelinaceae nas lavouras de arroz, conhecida vulgarmente por trapoerabinha (Murdannia nudiflora (L.) Brenans), tem despertado a atenção por sua rápida expansão nas áreas produtoras de grãos, devido a sua grande competitividade com a cultura e dificuldade de controle (Juliani et al., 2008).

A espécie é originaria da África e ocorre em varias regiões do mundo, é importante infestante na Colômbia, Venezuela e Bolívia (Kissmann e Groth, 1997). Na Guatemala, corresponde à espécie infestante mais nociva à cultura do arroz, causando prejuízos a partir dos 54 dias após a emergência da cultura (Sotomayor, 1988). Erasmo et. al. (2003) também relatam o aparecimento dessa espécie em regiões produtoras de arroz irrigado ao sul do Estado do Tocantins.

Essa espécie apresenta porte rasteiro, com formação de caule estolonífero, e dispersão via sementes (Kissmann e Groth, 1997). É uma planta daninha que ocorre em todo o Brasil, tendo-se notado o aumentando significativo da sua disseminação nos últimos anos em lavouras de soja sob plantio direto no estado do Mato Grosso (Lorenzi, 2000). Esse aumento na freqüência pode ser justificado pela pressão de seleção de espécies, que mais se adaptam a condições de distúrbio provocado pela mecanização e implantação de monocultivo. A propagação dessa espécie pode ser vegetativa ou por sementes, que apresentam dormência e podem permanecer viáveis no solo por longos períodos (Kissmann e Groth, 1997).

O balanço competitivo entre as comunidades infestantes e as culturas agrícolas depende de fatores relacionados a própria comunidade infestante (composição específica, densidade e distribuição), a cultura (espécie ou variedade, espaçamento e densidade de plantio), bem como a extensão do período de convivência, podendo esses fatores ser alterados pelas condições edafoclimáticas e pelos tratos culturais (Pitelli, 1985).

A determinação do fluxo de emergência de plantas daninhas no campo é uma importante ferramenta para o desenvolvimento de estratégias de manejo racionais e alternativas ao uso de herbicidas. Entretanto, diversas espécies apresentam dormência das sementes. Isto é um fator que dificulta a realização de pesquisas direcionadas ao manejo e ao controle destas plantas em áreas agrícolas (Rodrigues e Pitelli, 1994).

Dormência é o fenômeno no qual as sementes de uma determinada espécie, mesmo sendo viáveis e tendo condições ambientais para tanto, não germinam (Carvalho e Nakagawa, 2000). A dormência é um mecanismo de defesa das sementes contra as variações do ambiente, as quais dificultam ou impedem sua atividade metabólica normal (Marcos Filho, 2005). A germinação rápida e uniforme das sementes é de interesse para os estudos de manejo de plantas daninhas, principalmente para a avaliação de herbicidas aplicados em pós emergência (Santos et al., 2001; Vivian et al., 2008).

As plantas daninhas, em especial, dependem diretamente da germinação para infestar e competir com as espécies cultivadas (Roberts, 1999); deste modo, a promoção da germinação das espécies daninhas pode ser afetada por condições de luz, temperatura, ação de fitohormônios e umidade, que são variáveis durante o período de formação das sementes (Takahoshi, 1995).

Objetivou-se estudar a quebra de dormência de sementes de $M$. nudiflora, além de avaliar a resposta germinativa dessa espécie a diferentes qualidades de luz. 


\section{MATERIAL E MÉTODOS}

Os experimentos foram conduzidos no Laboratório de Sementes da Universidade do Estado de Mato Grosso (UNEMAT), Campus Universitário de Alta Floresta - MT.

Para estudar métodos de superação de dormência, foram colhidas sementes de $M$. nudiflora em área agrícola de cultivo de arroz de terras altas, na safra agrícola de 2007/08, no município de Alta Floresta - MT, situado nas coordenadas geográficas $9^{\circ} 52^{\prime} 10^{\prime \prime} \mathrm{S}$ e $56^{\circ} 07^{\prime} 02^{\prime \prime} \mathrm{W}$, com 289 metros de altitude. As sementes foram colocadas para secar em local seco e sombreado por sete dias, e posteriormente elas foram acondicionadas em sacos de papel e armazenadas em câmara de refrigeração a temperatura de $10{ }^{\circ} \mathrm{C}\left( \pm 2{ }^{\circ} \mathrm{C}\right)$ por três meses.

O presente trabalho constou de duas etapas experimentais. $\mathrm{Na}$ primeira etapa, avaliaram-se os tratamentos químicos ou físicos promissores na superação da dormência das sementes de $M$. nudiflora. Os tratamentos constituíram-se de: imersão em ácido sulfúrico absoluto por 30, 60 e 300 segundos; imersão em solução de hidróxido de sódio a $20 \%$ por 5,15 e 25 minutos; imersão em solução de hipoclorito de sódio a $2,5 \%$ por 24 horas; imersão em solução de nitrato de potássio (20 mM) por 24 e 48 horas; imersão em solução de ácido giberélico (1 mM) por 24 horas; escarificação mecânica através de fricção das sementes entre duas lixas n ${ }^{\circ} 180$ por 60 segundos; testemunha, onde as sementes foram colocadas diretamente para germinar. Em seguida, todas as sementes foram submetidas à lavagem com água destilada e posterior imersão em solução de hipoclorito de sódio a $2,5 \%$ por 10 minutos.

As sementes foram semeadas sobre duas folhas de papel Germitest ${ }^{\circledR}$, dispostas no interior de caixas de acrílico transparente $(11,0 \times 11,0 \times 3,5 \mathrm{~cm})$ tipo gerbox e umedecidas com quantidade de água destilada equivalente a 2,5 vezes o peso do papel (Brasil, 1992), e colocadas em câmaras de germinação padrão tipo B.O.D., com temperatura e fotoperíodo controlados $\left(25^{\circ} \mathrm{Ce} 12\right.$ horas de luz). Cada unidade experimental foi constituída de uma caixa acrílica tipo gerbox com 50 sementes, com 4 repetições de cada tratamento.

Foi avaliado a porcentagem de germinação e o índice de velocidade de germinação (IVG), esse último sendo calculado segundo fórmula proposta por Maguire (1962), como segue: $\mathrm{IVG}=[\mathrm{N} 1 / 1+\mathrm{N} 2 / 2+\mathrm{N} 3 / 3+\ldots+\mathrm{Nn} / \mathrm{n}]$, em que $\mathrm{N} 1$, $\mathrm{N} 2$, N3 e Nn são as porcentagens de sementes germinadas no primeiro, segundo, terceiro e enésimo dias após a semeadura. Foi realizada contagem do número de sementes germinadas diariamente, a partir da instalação de cada teste, durante 30 dias. Foi considerada germinada, a semente que originou plântula com radícula igual ou superior a $2 \mathrm{~mm}$ de comprimento (Rehman et al., 1996). As sementes germinadas, após a contagem, foram retiradas e descartadas, determinandose a sua porcentagem.

$\mathrm{Na}$ segunda etapa (após a determinação do melhor método para a superação da dormência das sementes de $M$. nudiflora), buscou-se avaliar a influência da qualidade da luz na germinação das sementes. Foi testada a influência da luz branca, verde, azul, vermelha e ausência de luz. As sementes foram escarificadas mecanicamente atritando-as entre duas lixas $n^{\circ} 180$ por 60 segundos, desinfestadas com imersão em solução hipoclorito de sódio a $2,5 \%$ por 10 minutos e colocadas para germinar em caixas acrílicas transparentes sobre duas folhas de papel Germitest ${ }^{\circledR}$ umedecidas com água destilada na proporção de 2,5 vezes seu peso.

Para obtenção das diferentes qualidades de luz, foram confeccionados os seguintes filtros: Filtro de luz azul, com reflexão máxima a $450 \mathrm{~nm}$; filtro de luz verde, com reflexão máxima a $500 \mathrm{~nm}$; filtro de luz vermelha, com reflexão máxima a $700 \mathrm{~nm}$; caixa plástica preta (ausência de luz); filtro transparente de luz branca (testemunha), praticamente sem reflexão na região do visível, ou seja, com transmissividade de $\lambda$ na região de 380 a $760 \mathrm{~nm}$.

Estes filtros foram constituídos de duas folhas de papel celofane de cor correspondente ao tratamento, adotando-se para a testemunha o transparente (luz branca), revestindo-se as caixas acrílicas (Usberti, 1979; Lopes et al., 2005).

A fonte de luz foi obtida através de quatro lâmpadas fluorescentes de 20 watts cada, totalizando 80 watts, dispostas na parte interna da porta da câmara de germinação.

Após este procedimento, as sementes foram submetidas ao teste de germinação como já descrito no experimento anterior.

A avaliação foi realizada no $15^{\circ}$ dia após a montagem do experimento. Foi considerada germinada, a semente que originou a plântula, com radícula igual ou superior a $2 \mathrm{~mm}$ de comprimento.

Para todos os experimentos, se utilizou o delineamento estatístico inteiramente casualizado, com 50 sementes em quatro repetições e os resultados foram submetidos à análise de variância, sendo as médias comparadas pelo teste Tukey a $5 \%$ de probabilidade.

\section{RESULTADOS E DISCUSSÃO}

Pelos dados da Tabela 1 verifica-se entre os diferentes métodos de superação de dormência de sementes de $M$. nudiflora que a escarificação mecânica com lixa n.180 por 
60 segundos proporcionou germinação superior aos demais tratamentos, alcançado uma média de $84 \%$ de germinação. Esse método laboratorial, muito utilizado para quebra de dormência de sementes de plantas invasoras, permite a remoção mecânica do tegumento, facilitando a entrada de água e gases. Como a maioria dessas plantas apresenta sementes diminutas, como é o caso de M. nudiflora, a prática mais comum é a abrasão por intervalos de tempo (Mikusinski, 1987; Rodrigues e Pitelli, 1994; Silva et al., 2009).

TABELA 1. Percentuais germinativos de sementes de Murdannia nudiflora, submetidas à escarificação mecânica e química.

\begin{tabular}{llc}
\hline TRATAMENTOS & \multicolumn{3}{c}{ GERMINAÇÃO (\%) } \\
\hline Escarificação Mecânica & \multicolumn{2}{c}{$84 \mathrm{~A}$} \\
Ácido sulfúrico/60s & 74 & $\mathrm{~B}$ \\
Hipoclorito de sódio/24h & 46 & $\mathrm{C}$ \\
Hidróxido de sódio/25m & 26 & $\mathrm{D}$ \\
Ácido sulfúrico/30s & 10 & $\mathrm{E}$ \\
Soda cáustica/15m & 0 & $\mathrm{~F}$ \\
Nitrato de potássio/24h & 0 & $\mathrm{~F}$ \\
Nitrato de potássio/48h & 0 & $\mathrm{~F}$ \\
Ácido sulfúrico/300s & 0 & $\mathrm{~F}$ \\
Ácido giberélico/24h & 0 & $\mathrm{~F}$ \\
Testemunha & 0 & $\mathrm{~F}$ \\
\hline C.V. (\%) & \multicolumn{3}{c}{10,84}
\end{tabular}

Médias seguidas de mesma letra, não diferem entre si a $5 \%$ de probabilidade pelo teste de Tukey.

A eficiência da escarificação mecânica foi também constatada por Marques (1991) e Franke e Baseggio (1998) para Desmodium incanum DC.; Medeiros e Nabinger (1996) para Adesmia muricata (Jacq) DC e Trifolium resupinatum L.; Martins et al. (1997) para Desmodium tortuosum (Sw.) DC., Jacob Junior et al. (2004) para Lotus subbiflorus L e Salvador et al. (2007) para Ipomoea nil e Euphorbia heterophylla, cujas sementes apresentam características de dureza. Esse atrito, que em ambiente agrícola, pode ser resultante do preparo do solo, promove novo fluxo de emergência, reduzindo o número de sementes no banco (Bridgemohan et al., 1991).

Por outro lado, esse tratamento não se mostrou eficiente na superação da dormência de sementes de Lathyrus nervosus Lam. (Franke e Baseggio, 1998). Segundo esses autores, tais resultados podem ser explicados pela ocorrência de injúrias nas sementes provocadas pela fricção mecânica ou pela diferença de constituição do tegumento das sementes diferentes espécies daninhas.

Verificou-se também que a escarificação química com imersão em ácido sulfúrico por 60 segundos (Tabela 1) proporcionou germinação superior aos demais tratamentos, não sendo superior apenas ao tratamento com escarificação mecânica. Erasmo et al. (2008) relataram que o tratamento mais favorável à superação da dormência das sementes de $M$. nudiflora foi o pré-aquecimento, a $40^{\circ} \mathrm{C}$, em substrato úmido, por três semanas, seguido pela escarificação mecânica por 40 fricções e pela imersão das sementes em ácido sulfúrico por 40 segundos.

Em outros estudos, o tratamento com ácido sulfúrico também foi avaliado em Commelina benghalensis, o qual proporcionou as maiores porcentagens de germinação e incremento de $157 \%$ em relação à testemunha, enquanto que a escarificação mecânica proporcionou aumentos de $63 \%$ (Rodrigues e Pitelli, 1994).

Os tratamentos químicos e mecânicos testados propiciaram considerável germinação das sementes, sendo possível inferir que a dormência desta espécie pode estar relacionada à impermeabilidade do tegumento. Isso se justifica pela dificuldade da entrada de água e gases necessários para estimular a germinação.

Os tratamentos químicos com ácido sulfúrico por 30 segundos, hidróxido de sódio por 25 minutos e hipoclorito por 24 horas também favoreceram a germinação de sementes de $M$. nudiflora, mas foram inferiores aos valores obtidos no tratamento com ácido sulfúrico por 1 minuto e escarificação mecânica (Tabela 1).

$\mathrm{O}$ maior vigor de sementes submetidas à escarificação química e física (Tabela 2) reforça os resultados obtidos na contagem de sementes germinadas. A maioria das sementes de M. nudiflora germinou nos primeiros 12 dias de incubação havendo sementes germinadas até os 15 dias de avaliação (Figura 1).

Baseando-se nos resultados anteriores, procedeuse à escarificação mecânica das sementes de Murdannia nudiflora, que posteriormente foram postas para germinar sob diferentes qualidades de luz. Os resultados encontramse expressos na Tabela 3. Observou-se que apesar de o filtro vermelho ter reduzido em $14 \%$ a germinação, este não diferiu significativamente da testemunha (luz branca), sendo que o filtro verde não diferiu do filtro vermelho, mas diferiu do filtro transparente. O filtro azul não diferiu significativamente do filtro verde, mas se comparado aos filtros vermelho e transparente houve diferença significativa. A caixa plástica 
preta (ausência de luz) reduziu significativamente a geminação das sementes de Murdannia nudiflora quando comparado aos demais filtros. Esse comportamento demonstrou que as sementes dessa espécie podem ser classificadas como fotoblástica positiva, pois dependem da luz para ocorrer germinação.

TABELA 2. Índice de velocidade de germinação (IVG) em tratamentos para superação de dormência de sementes de Murdannia nudiflora.

\begin{tabular}{llll}
\hline TRATAMENTOS & \multicolumn{2}{c}{ IVG } \\
\hline Escarificação Mecânica & $5,91 \mathrm{~A}$ & \\
Ácido sulfúrico/60s & 5,25 & $\mathrm{~B}$ & \\
Hipoclorito de sódio/24h & 3,46 & $\mathrm{C}$ & \\
Hidróxido de sódio/25m & 0,81 & $\mathrm{D}$ \\
Ácido sulfúrico/30s & 0.73 & $\mathrm{D}$ \\
Soda cáustica/15m & 0,00 & $\mathrm{E}$ \\
Nitrato de potássio/24h & 0,00 & $\mathrm{E}$ \\
Nitrato de potássio/48h & 0,00 & $\mathrm{E}$ \\
Ácido sulfúrico/300s & 0,00 & $\mathrm{E}$ \\
Ácido giberélico/24h & 0,00 & $\mathrm{E}$ \\
Testemunha & 0,00 & $\mathrm{E}$ \\
\hline C.V. (\%) & 15,76 & \\
\hline
\end{tabular}

Médias seguidas de mesma letra, não diferem entre si a 5\% de probabilidade pelo teste de Tukey.

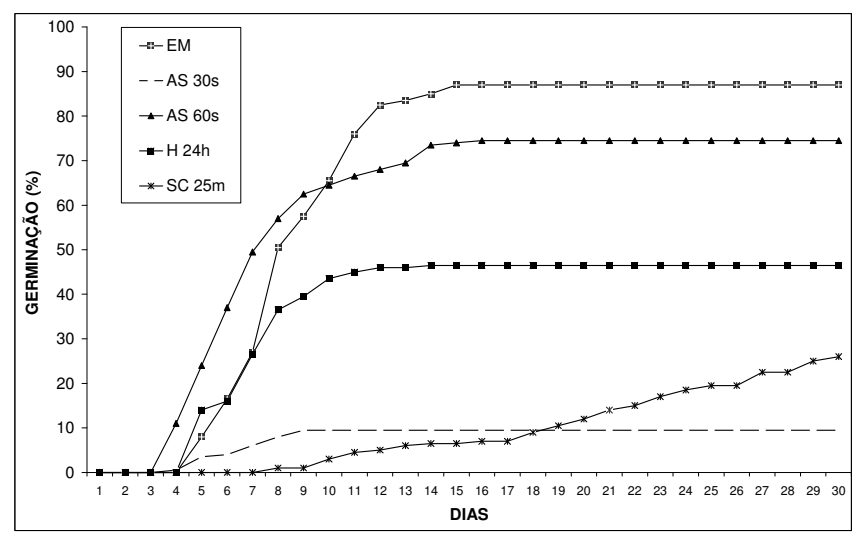

FIGURA 1. Germinação acumulada de sementes de Murdannia nudiflora, submetidas aos tratamentos de quebra de dormência escarificação mecânica (EM), ácido sulfúrico/30s (AS 30s), ácido sulfúrico/60s (AS 60s), hipoclorito de sódio/24h (H 24h) e soda cáustica/25m (SC $25 \mathrm{~m})$.
TABELA 3. Efeitos de diferentes filtros de luz na germinação de sementes de Murdannia nudiflora.

\begin{tabular}{|c|c|}
\hline TRATAMENTOS & GERMINAÇÃO (\%) \\
\hline Filtro transparente & $87 \mathrm{~A}$ \\
\hline Filtro vermelho & $75 \mathrm{AB}$ \\
\hline Filtro verde & $64 \mathrm{BC}$ \\
\hline Filtro azul & 58 \\
\hline Ausência de luz & 1,0 \\
\hline C.V. (\%) & 11,23 \\
\hline
\end{tabular}

Médias seguidas de mesma letra, não diferem entre si a $5 \%$ de probabilidade pelo teste de Tukey.

Toledo et al. (1993) relataram que os filtros verde, vermelho, azul e ausência de luz reduziram em mais de 50\% a germinação de sementes de Xanthium strumarium L., mas não diferindo estatisticamente da testemunha (luz branca), embora estatisticamente possa ser considerada espécie fotoblástica positiva, este caráter é apenas quantitativo, uma vez que tanto na presença quanto na ausência de luz, ocorreu considerável germinação de suas sementes. Este comportamento pode ser considerado corno um fotoblastismo preferencial.

A luz tem sido reconhecida como um requerimento para a germinação de sementes de muitas espécies de plantas daninhas. Estas sementes, em geral, são pequenas e contêm relativamente pouca reserva nutritiva e, com isso, a germinação sobre ou próxima à superfície do solo é necessária a sua sobrevivência (Vivian et al., 2008). O requerimento de luz é a principal razão pela qual a germinação de sementes é restrita à proximidade da superfície do solo. Muitos solos atenuam efetivamente a penetração da luz. Dessa forma, luz suficiente para induzir a germinação está presente apenas nos primeiros milímetros da superfície do solo. Em solos agrícolas, muitas sementes são revolvidas pelo cultivo e podem germinar apenas quando re-expostas à luz no cultivo subseqüente (Kogan, 1992; Wolley e Stoller, 1978).

\section{CONCLUSÕES}

O melhor método para superação da dormência das sementes de M. nudiflora é a escarificação mecânica através de fricção das sementes entre duas lixas $n^{0} 180$ por 60 segundos.

Sementes de Murdannia nudiflora apresentam compor- 
tamento fotoblástico positivo.

\section{REFERÊNCIAS}

BRASIL. Ministério da Agricultura e Reforma Agrária. Secretaria Nacional de Defesa Agropecuária. Departamento Nacional de Produção Vegetal. Coordenação de Laboratório Vegetal. Regras para Análise de Sementes. Brasília, DF, 1992. 365p

BRIDGEMOHAM, P.; BRATHWAITE, R.A.I.; MAC DAVI, C.R. Seed survival and patterns of seedling emergence studies of Rottboellia cochinchinensis Clayton in cultivated soils. Weed Research, v.31, n.5, p.265-72, 1991.

CARVALHO, N.; NAKAGAWA, J. Sementes: ciência, tecnologia e produção. 4.ed. FUNEP, Jaboticabal. 2000. $588 \mathrm{p}$.

ERASMO, E.A.L., TERRA, M.A.; DOMINGOS, V.D.; MARTINS, C.C.; COSTA, N.V. Superação da dormência em sementes de Murdannia nudiflora (L.) Brenan. Acta Scientiarum Agronomy, v.30, n.2, p.273-277, 2008.

ERASMO, E.A.L.; TERRA, M.A.; COSTA, N.V.; DOMINGOS, V.D.; DIDONET, J. Fenologia e acúmulo de matéria seca em plantas de Murdannia nudiflora durante seu ciclo de vida. Planta Daninha, v.21, n.3, p.397-402, 2003.

FRANKE, L.B.; BASEGGIO, L. Superação da dormência em sementes de Desmodium incanum DC e Lathyrus nervosus Lam. Revista Brasileira de Sementes, v.20, n.2, p.420-424, 1998.

JACOB JUNIOR, E.A.; MENEGHELLO, G.E.; MELO, P.T.B.S.; MAIA, M.S. Tratamentos para superação de dormência em sementes de cornichão anual. Revista Brasileira de Sementes, v.26, n.2, p 15-19, 2004.

JULIANI, J.; RIBEIRO, P.C.; NEVES, R.; CERIANI, C. Efeito da matocompetição precoce na produtividade da soja transgênica, resistente ao glifosato. In: CONGRESO DE LA ASOCIACIÓN LATINOAMERICANA DE MALEZAS, 18., Ouro Preto, 2008. Anais... Ouro Preto: ALAM: 1 CD. 2008.

KISSMANN, K.G.; GROTH, D. Plantas infestantes e nocivas. 2.ed. São Paulo. BASF, Tomo 1. 110 p., 1997.

KOGAN, M.A. Malezas: ecofisiologia y estratégias de control. Santiago: Pontificia Universidad Catolica, 1992.402p.

LOPES, J.C.; CAPUCHO, M.T.; MARTINS FILHO, S.; REPOSSI, P.A. Influência de temperatura, substrato e luz na germinação de sementes de bertalha. Revista Brasileira de Sementes, v.27, n.2, p.18-24, 2005.
LORENZI, H. Plantas daninhas do Brasil: terrestres, aquáticas, parasitas e tóxicas. 3.ed. Nova Odessa: Plantarum, 2000. $112 \mathrm{p}$.

MAGUIRE, J.D. Speed of germination-aid in relation evaluation for seedling emergence vigor. Crop Science, v.2, n.2, p.176-177, 1962.

MARCOS FILHO, J. Fisiologia de sementes de plantas cultivadas. Piracicaba: FEALQ, 2005. 495p.

MARQUES, M.A.I. Características agronômicas e reprodutivas de espécies do gênero Desmodium desv. 1991. 75f. Dissertação (Mestrado em Agronomia) - Universidade Federal do Rio Grande do Sul, Porto Alegre.

MARTINS, C.C.; SILVA, W.R.; CARVALHO, D.D. Efeitos de tratamentos térmicos sobre o desempenho de sementes de Panicum maximum Jacq. In: REUNIÃO ANUAL DA SOCIEDADE BRASILEIRA DE ZOOTECNIA, 2., Fortaleza, 1997. Anais... Fortaleza: SBZ: p.277-279. 1997.

MEDEIROS, R.B.; NABINGER, C. Superação da dormência em sementes de leguminosas forrageiras. Revista Brasileira de Sementes, v.18, n.2, p.193-199, 1996.

MIKUSINSKI, O.M. Testes de embebição e germinação em sementes de Ipomoea aristolochiaefolia. Revista Brasileira de Sementes, v.9, n.3, p.103-108, 1987.

PITELLI, R.A. Interferência das plantas daninhas em culturas agrícolas. Informe Agropecuário, Belo Horizonte, v.11, n.129, p.16-27, 1985.

REHMAN, S.; HARRIS, P.J.C.; BOURNE, W.F.; WILKIN, $\mathrm{J}$. The effect of sodium chloride on germination and the potassium and calcium contents of Acacia seeds. Seed Science and Technology, v.25, n.1, p.45-57, 1996.

ROBERTS, E.H. A search for pattern and form. Seed Science Research, v.9, n.1, p. 181-208, 1999.

RODRIGUES, B.N.; PITELLI, R.A. Quebra de dormência em sementes de Commelina benghalensis. Planta Daninha, v.12, n.2, p.106-110, 1994.

SANTOS, I.C.; FERREIRA, F.A.; MIRANDA, G.V.; SANTOS, L.D.T. Germinação de sementes aéreas e subterrâneas de Commelina benghalensis. Planta Daninha, v.19, n.2, p.163-170, 2001.

SILVA，C.E.B.; PARREIRA，M.C.; ALVES，P.L.C.A.; PAVANI, M.C.M.D. Aspectos germinativos de capimcamalote (Rottboellia cochinchinensis). Planta Daninha, v.27, n.2, p.273-281, 2009.

SOTOMAYOR, D.J.I. Determination del periodo crítico de interferência maleza arroz (Oryza sativa L.) en el 
parcelamiento Caballo Blanco. Guatemala Agriculture, p.118-121, 1988.

TAKAHOSHI, N. Physiology of dormancy. In: MATSUO, T. et al. Science of the rice plant. Tokyo: Food and Agriculture Policy Research Center, 1995, v.2. p. 45-65,

TOLEDO, R.E.B.; KUVA, M.A.; ALVES, P.L.C.A. Fatores que afetam a germinação e a emergência de Xanthium strumarium L.: dormência, qualidade da luz e profundidade de semeadura. Planta Daninha, v.11, n.1/2, p.15-20, 1993.

USBERTI, R. Estudo da germinação de sementes de limão cravo (Citrus reticulata var. austera Hib-wingle): condições de umidade e armazenamento e relações hormonais. 1979. 70 f. Dissertação (Mestrado em Fisiologia Vegetal) - Universidade de Campinas, Campinas.

VIVIAN, R.; SILVA, A.A.; GIMENES, Jr., M.; FAGAN, E.B.; RUIZ, S.T.; LABONIA, V Dormência em sementes de plantas daninhas como mecanismo de sobrevivência - breve revisão. Planta Daninha, v.26, n.3, p.695-706, 2008.

WOLLEY, J.L.; STOLLER, E.W. Light penetration and light-p induced seed germination in soil. Plant Physiology, v.61, p.597, 1978. 